\title{
Social interaction contexts bias the perceived expressions of interactants
}

Article

Accepted Version

Gray, K. L. H., Barber, L., Murphy, J. and Cook, R. (2017)

Social interaction contexts bias the perceived expressions of interactants. Emotion, 17 (4). pp. 567-571. ISSN 1931-1516 doi: https://doi.org/10.1037/emo0000257 Available at https://centaur.reading.ac.uk/68482/

It is advisable to refer to the publisher's version if you intend to cite from the work. See Guidance on citing.

To link to this article DOI: http://dx.doi.org/10.1037/emo0000257

Publisher: American Psychological Association

All outputs in CentAUR are protected by Intellectual Property Rights law, including copyright law. Copyright and IPR is retained by the creators or other copyright holders. Terms and conditions for use of this material are defined in the End User Agreement.

\section{www.reading.ac.uk/centaur}

\section{CentAUR}

Central Archive at the University of Reading

Reading's research outputs online 
Submitted to: Emotion

Format: Brief Report

Running head: Interaction contexts bias expression perception

Word count: 2481

Revision submission date: 26/07/2016

\title{
Social interaction contexts bias the perceived expressions of interactants
}

\author{
Katie L.H. Gray ${ }^{1 *}$, Lee Barber ${ }^{1}$, Jennifer Murphy ${ }^{2,3}$, Richard Cook $^{2}$
}

${ }^{1}$ School of Psychology and Clinical Language Sciences, University of Reading, Reading, U.K.

${ }^{2}$ Department of Psychology, University City London, London, U.K.

${ }^{3}$ MRC Social, Genetic and Developmental Psychiatry Centre, Institute of Psychiatry, Psychology, and Neuroscience, King's College London, London, U.K.

*Corresponding author:

K.L.H.Gray@Reading.ac.uk Psychology and Clinical Language Sciences

University of Reading

Reading, UK

RG6 6AU 


\begin{abstract}
The present study sought to determine whether contextual information available when viewing social interactions from third-person perspectives, may influence observers' perception of the interactants' facial emotion. Observers judged whether the expression of a target face was happy or fearful, in the presence of a happy, aggressive or neutral interactant. In two experiments, the same target expressions were judged to be happier when presented in the context of a happy interactant, than when interacting with a neutral or aggressive partner. We failed to show that the target expression was judged as more fearful when interacting with an aggressive partner. Importantly, observers' perception of the target expression was not modulated by the emotion of the context interactant when the interactants were presented back-to-back, suggesting that the bias depends on the presence of an intact interaction arrangement. These results provide valuable insight into how social contextual effects shape our perception of facial emotion.
\end{abstract}

\title{
Key words:
}

Social interactions; contextual modulation; expression recognition 


\section{Introduction}

Interpreting facial emotion accurately is essential for successful navigation of one's social environment (Adolphs, 2002). Previous research indicates that the perception of facial emotion is informed by our knowledge and experience (de Gelder et al., 2006; FeldmanBarrett, Mesquita, \& Gendron, 2011). For example, the same facial expression varies in appearance when presented in the context of different body postures (Aviezer, Trope, \& Todorov, 2012). The perceived expression of a target face is also affected by vocal cues (de Gelder \& Vroomen, 2000), concurrently presented visual scenes (Righart \& de Gelder, 2008), and surrounding faces (in Japanese, but not Western participants; Masuda et al., 2008). The influence of context often occurs despite explicit instructions to disregard extraneous information (Aviezer, Bentin, Dudarev, \& Hassin, 2011). However, susceptibility to context effects can be affected by socio-psychological factors such as personality (Lee, Choi, \& Cho, 2012), and the type of contextual cue (Ngo \& Isaacowitz, 2015).

The present study sought to determine whether contextual information available when viewing social interactions from third-person perspectives, influences observers' perception of the interactants' facial emotion. Correctly interpreting social interactions has enormous adaptive value, facilitating social learning (e.g., acquisition of sporting, dancing, and self-defence skills) and guiding social behaviours (e.g., one may offer a flirting couple privacy, but intervene to stop an aggressive confrontation). Nevertheless, remarkably little is known about the perceptual mechanisms underlying the visual analysis of social interactions. While considerable research has addressed the perception of individuals, there is a dearth of knowledge about the dedicated visual mechanisms recruited by interactions (Mobbs et al., 2006; Sinke, Sorger, Goebel, \& de Gelder, 2009).

Crucially, characteristic patterns of gaze direction and facial expressions are used to interpret interactions (Knapp, Hall, \& Horgan, 2013; Thayer \& Schiff, 1974). These nonverbal cues support consistent judgments about the nature of interactions (e.g., the detection of bullying; Craig, Pepler, \& Atlas, 2000), and the character traits of the interactants (e.g. the inference of dominance; Schmid-Mast \& Hall, 2004). Because the facial emotion of one interactant reliably predicts the expressions of others, we reasoned that the expression of a task-irrelevant ('context') interactant may bias the perceived expression of a task-relevant ('target') interactant, when observers view interacting dyads. 


\section{Experiment 1}

At least two types of perceptual bias may be induced by social interaction contexts. First, humans have a pervasive tendency to imitate (Heyes, 2011) and reciprocate displays of facial emotion (Sato \& Yoshikawa, 2007). Exposure to these matching contingencies may foster a congruency bias whereby the perceived expression of a target interactant is attracted towards the expression of the context interactant. Second, patterns of covariation present in social interactions may encourage complementary biases, whereby the expression of one interactant predicts the associated expression. Importantly, not all types of interaction are imitative; sometimes the behaviour of one interactant predicts nonmatching, complementary behaviours in another (Tiedens \& Fragale, 2003). Experiment 1 sought evidence for one or both of these biases.

\section{Participants}

Thirty-four naïve adults $\left(M_{\text {age }}=25.65 ; S D_{\text {age }}=6.91 ; 12\right.$ males $)$ with normal or correctedto-normal vision participated in Experiment 1. Sample size was determined a priori based on counterbalancing constraints and power analysis conducted assuming a large effect size (Cohen, 1988). Ethical clearance was granted by the local ethics committee and the study was conducted in line with the ethical guidelines laid down in the $6^{\text {th }}$ (2008) Declaration of Helsinki.

\section{Materials and Methods}

We employed a psychophysical procedure, in which participants made binary decisions ('Happy' or 'Fearful'?) about the expression of a target interactant in the presence of a neutral, happy or aggressive context interactant. This design allowed us to test for both congruency and complementary biases: Relative to a neutral context baseline, a tendency to perceive the target interactant as happier in the presence of a happy context interactant would reveal a congruency bias; a tendency to perceive the target interactant as more fearful in the presence of an aggressive interactant, would reveal a complementary bias.

Interactants were presented in profile, facing each other. Images were taken from the Radboud Faces Database (Langner et al., 2010). When viewed at $57.3 \mathrm{~cm}$, each subtended $6^{\circ}$ of visual angle vertically, with an inter-interactant-distance of $3^{\circ}$. Three different male faces were used to define aggressive, happy, and neutral contexts (see Figure 1b). The 
identity of the context interactants was held constant. The expression of a target female interactant was parametrically manipulated between happy and fearful in seven equidistant steps of 10\% (80-20\% happy-fear; 70-30\% happy-fear; 60-40\% happy-fear; 50-50\% happy-fear; 40-60\% happy-fear; 30-70\% happy-fear; 20-80\% happy-fear) using Morpheus Photo Morpher Version 3.11 (Morpheus Software, Inc.; see Figure 1a). The prototypical expressions used to construct the morph continuum received similar intensity ratings in the validation study (both 4.27 / 5.00). The happy, neutral, and aggressive context expressions were awarded intensity ratings of 4.21, 2.55, and 4.00, respectively (Langner et al., 2010).

Each trial presented the context interactant for $2000 \mathrm{~ms}$ before the onset of the target interactant. The target was presented alongside the context for a further $500 \mathrm{~ms}$, before their simultaneous offset. Observers categorised the expression of the target via keyboard responses. Context expression and level of target expression were randomly interleaved. Whether context and target interactants appeared on the left or right of fixation was counterbalanced to encourage participants to attend equally to both sides of the display. The experiment began with six practice trials, and concluded after 252 experimental trials ( 3 context conditions $\times 7$ levels of target expression levels $\times 12$ repetitions of each target level). The experiment was programmed in MATLAB (The MathWorks, Inc.) using Psychtoolbox (Brainard, 1997; Pelli, 1997).

\section{Results and Discussion}

For each observer, separate psychometric functions were estimated for each of the three context conditions. Cumulative Gaussian functions were fitted using the Palamedes toolbox (Prins \& Kingdom, 2009). PSE and slope were free to vary; guess and lapse rates were fixed at 0 and 0.01 , respectively. Similar goodness-of-fit deviance scores were seen in each condition $\left(M_{\text {happy }}=5.38 ; S D_{\text {happy }}=3.02 ; M_{\text {neutral }}=5.16, S D_{\text {neutral }}=2.94 ; M_{\text {aggressive }}=\right.$ $\left.5.99, S D_{\text {aggressive }}=2.67\right)$. The influence of context emotion was measured by calculating the point on the fear-happy morph continuum at which observers were equally likely to judge the target emotion as happy or fearful (the point of subjective equivalence; PSE). The distribution of PSEs was analysed using ANOVA with Interactant Context (happy, neutral, aggressive) as a within-subjects factor (see Figure 1c). The analysis revealed a significant effect of Interactant Context $\left[F(2,66)=5.34, p=.007, \eta_{p}{ }^{2}=.14\right]$. The target 
face required less happiness to be equally likely to be judged happy or fearful in the presence of the happy interactant $(M=49.45, S D=13.54)$, than in the presence of the neutral interactant $(M=51.87, S D=10.59)[t(33)=2.02, p=.052]$. The target face also required less happiness to be equally likely to be judged happy or fearful in the presence of the happy interactant than the aggressive interactant $(M=54.34, S D=11.78)[t(33)=$ $2.90, p=.007]$. Observers' perception of the target did not differ in the presence of the neutral and aggressive interactants $[t(33)=1.00, p>.250]$.

\section{Experiment 2}

The results of Experiment 1 suggest that observers' perceptions of the target expression were biased by the expression of a context interactant. It is possible, however, that these effects do not reflect contextual modulation by social interaction per se, but are simply induced by the presence of a second face. If the bias is a product of priming - where unrelated faces surrounding a target face encourage particular judgments about facial expressions (Masuda et al., 2008) - or perceptual averaging - where perceived expressions of individual faces are biased towards the average expression extracted from facial arrays (Haberman \& Whitney, 2007) - similar effects should be seen irrespective of the faces' spatial arrangement. To examine the specificity of the context effect, we compared the bias induced when the interactants faced towards each other (face-to-face), and away from each other (back-to-back). If the bias depends on the presence of an intact interaction arrangement, the effect should be eliminated by back-to-back presentation.

\section{Participants}

Sixty naïve adults with normal or corrected-to-normal vision participated in Experiment 2. Participants were allocated to the face-to-face $\left(M_{\text {age }}=20.80, S D_{\text {age }}=4.65 ; 4\right.$ males $)$ and back-to-back $\left(M_{\text {age }}=27.1, S D_{\text {age }}=5.81 ; 10\right.$ males $)$ conditions in equal numbers.

\section{Materials and Methods}

The interaction arrangements in the face-to-face condition closely resembled those employed in Experiment 1. Back-to-back arrangements were constructed by mirroring each interactant from the face-to-face condition about their vertical axis (see Figure 2c). In Experiment 1, the identity of the three context interactants (happy, aggressive, neutral) was held constant for all observers. Because this procedure confounded the identity and expression of the context interactant, it is possible that the bias was induced by the 
presence of an attractive or trustworthy interactant (Todorov, Said, Engell, \& Oosterhof, 2008). To control for this possibility, we counterbalanced the identities used in the context conditions. Thus, within each alignment condition ten observers saw context-face A as the aggressor, ten saw context-face $\mathrm{B}$ as the aggressor, and ten saw context-face $\mathrm{C}$ as the aggressor, and so on. The happy, neutral, and aggressive contexts were awarded mean intensity ratings of 4.25, 3.02, and 3.78 in the validation study (Lagner et al., 2010).

The procedure was similar to the first experiment, with the following exceptions. First, the presentation duration of the context interactant was reduced to $1500 \mathrm{~ms}$ in total $(1000 \mathrm{~ms}$ presentation before the onset of the target interactant) to reduce the length of each trial. Second, the number of repetitions per morph-level was increased to 16 . Thus, there were 336 experimental trials ( 3 contexts $\times 7$ levels of target expression $\times 16$ repetitions) in each arrangement condition (face-to-face, back-to-back).

\section{Results and Discussion}

Separate psychometric functions were estimated for each observer, for each context condition. Similar goodness-of-fit deviance scores were seen in the three contexts (in the face-to-face condition: $M_{\text {happy }}=3.75 ; S D_{\text {happy }}=1.82 ; M_{\text {neutral }}=3.92, S D_{\text {neutral }}=2.40$; $M_{\text {aggressive }}=3.75, S D_{\text {aggressive }}=2.33$; and back-to-back condition: $M_{\text {happy }}=3.81 ; S D_{\text {happy }}=$ $\left.1.79 ; M_{\text {neutral }}=3.80, S D_{\text {neutral }}=2.38 ; M_{\text {aggressive }}=3.39, S D_{\text {aggressive }}=2.10\right)$. The distribution of PSEs (Figure 2b) was analysed using ANOVA with Interactant Context (happy, neutral, aggressive) as a within-subjects factor, and Alignment (face-to-face, back-to-back) as a between-subjects factor. The analysis revealed a significant Interactant Context $\times$ Alignment interaction $\left[F(2,116)=6.18, p=.003, \eta_{p}{ }^{2}=.10\right]$. In the face-to-face condition, there was a significant main effect of Interactant Context $\left[F(2,58)=11.34, p<.001, \eta_{p}{ }^{2}\right.$ $=.28$ ], replicating the results from Experiment 1 (see Figure 2a). Once again the target face required less happiness to be to be equally likely to be judged happy or fearful in the presence of the happy interactant $(M=50.97, S D=10.27)$, than in the presence of the neutral $(M=55.96, S D=10.84)[t(29)=3.51, p=.001]$, or aggressive interactants $(M=$ $57.42, S D=10.84)[t(29)=3.92, p<.001]$. As in Experiment 1 , observers' judgments of the target expression did not differ in the presence of the neutral and aggressive interactants $[t(29)=1.01, p>.250]$. Unlike the face-to-face condition, however, 
observers' judgments of the target expression in the back-to-back condition did not vary as a function of Interactant Context $\left[F(2,58)=1.10, p>.250, \eta_{p}{ }^{2}=.04\right]$.

\section{Discussion}

Previous findings indicate that contextual information can bias observers' interpretation of facial emotion (Aviezer et al., 2011; 2012; de Gelder \& Vroomen, 2000; Righart \& de Gelder, 2008), underscoring how knowledge and experience shape our perception (de Gelder et al., 2006; Feldman-Barrett, Mesquita, \& Gendron, 2011). Our results extend this literature, providing the first evidence that the expression of one interactant influences the perceived expression of another, when observers view social interactions from thirdperson-perspectives. In two experiments the same ambiguous target expressions were judged to be happier when presented in the context of a happy interactant, than when interacting with a neutral or aggressive partner.

The bias induced by the task-irrelevant expression was not seen when the interactants were presented back-to-back. For some observers, unrelated faces surrounding a target face may prime particular expression percepts (Masuda et al., 2008). Similarly, the perceived expressions of individual faces may be biased towards the average expression extracted from facial arrays (Haberman \& Whitney, 2007). Importantly, the absence of a back-to-back effect argues against priming or averaging accounts of the bias observed. Nor does the modulation appear to reflect psychophysical adaptation induced by fixation on the context face at the start of each trial. Crucially, adaptation induces a repulsion bias, whereby subsequently viewed expressions seem less like the adapting stimulus (Webster \& MacLeod, 2011). In contrast, the modulation described here is an attraction effect; perception of the target expression was biased towards the expression of the context interactant.

Instead, we favour the view that detection of one interactant suggests perceptual hypotheses about the other, derived from internal models of social interactions (Friston, 2005; Gregory, 1997). The process of reconciling actual and predicted visual inputs may give rise to the illusory bias observed. Humans exhibit a striking tendency to imitate (Heyes, 2011) and reciprocate displays of emotion (Sato \& Yoshikawa, 2007). Exposure to these imitative contingencies may exert a pervasive influence on internal models of 
social interaction. Insofar as rapid, automatic integration of visual features from different interaction partners may depend on the presence of an intact interaction arrangement, the modelling processes responsible for the bias may not be recruited when arrangements are broken by back-to-back presentation. In the absence of obligatory interaction processing, it may be easier to disregard the task-irrelevant expression.

Contrary to our speculation that ambiguous expressions might be judged more fearful in the presence of an aggressive interactant, we found no evidence for a complementary bias. While the sight of a fearful interactant may be more likely than a happy interactant in the presence of an aggressor, the strength of this complementary contingency may relatively weak. For example, in the presence of an aggressive context interactant, observers might equally expect the target to exhibit reciprocal aggression. It is also possible that the neutral expressions employed in the baseline condition, were themselves perceived as threatening (e.g. Lee, Kang, Park, Kim, \& An, 2008). Consistent with this possibility, when paired with a neutral interactant, the happy-fear PSE exceeded 50\% in both experiments (the morphed faces were judged as more fearful than happy). Negative interpretations of the neutral expression may make it harder to detect perceptual shifts induced by aggressors.

In summary, the same target expressions were judged to be happier when presented in the context of a happy interactant, than when interacting with a neutral or aggressive partner. Observers' perception of the target expression was not modulated by interaction context when the interactants were presented back-to-back, suggesting that the bias depends on the presence of an intact interaction arrangement. These results provide valuable insight into how social contexts shape our perception of facial emotion. 


\section{Acknowledgements}

K.L.H.G. was supported by an Experimental Psychology Society award. 


\section{References}

Adolphs, R. (2002). Recognizing emotion from facial expressions: psychological and neurological mechanisms. Behavioral and Cognitive Neuroscience Reviews, 1(1), 21-62.

Aviezer, H., Bentin, S., Dudarev, V., \& Hassin, R. R. (2011). The automaticity of emotional face-context integration. Emotion, 11(6), 1406-1414.

Aviezer, H., Trope, Y., \& Todorov, A. (2012). Holistic person processing: faces with bodies tell the whole story. Journal of Personality and Social Psychology, 103(1), 20-37.

Brainard, D. H. (1997). The psychophysics toolbox. Spatial Vision, 10(4), 433-436.

Cohen, J. (1988). Statistical Power Analysis for the Behavioral Sciences (Second Edition). Hillsdale, NJ: Lawrence Erlbaum Associates.

Craig, W. M., Pepler, D., \& Atlas, R. (2000). Observations of bullying in the playground and in the classroom. School Psychology International, 21(1), 22-36.

de Gelder, B., Meeren, H. K. M., Righart, R., Van den Stock, J., van de Riet, W. A. C., \& Tamietto, M. (2006). Beyond the face: exploring rapid influences of context on face processing. Progress in Brain Research, 155, 37-48.

de Gelder, B., \& Vroomen, J. (2000). The perception of emotions by ear and by eye. Cognition \& Emotion, 14(3), 289-311.

Feldman-Barrett, L., Mesquita, B., \& Gendron, M. (2011). Context in emotion perception. Current Directions in Psychological Science, 20(5), 286-290.

Friston, K. (2005). A theory of cortical responses. Philosophical Transactions of the Royal Society B-Biological Sciences, 360(1456), 815-836. 
Gregory, R. L. (1997). Knowledge in perception and illusion. Philosophical Transactions of the Royal Society B-Biological Sciences, 352(1358), 1121-1127.

Haberman, J., \& Whitney, D. (2007). Rapid extraction of mean emotion and gender from sets of faces. Current Biology, 17(17), R751-753.

Heyes, C. (2011). Automatic imitation. Psychological Bulletin, 137(3), 463-483.

Knapp, M., Hall, J., \& Horgan, T. (2013). Nonverbal communication in human interaction (eigth edition). Boston, MA: Wadsworth, Cengage Learning.

Langner, O., Dotsch, R., Bijlstra, G., Wigboldus, D. H. J., Hawk, S. T., \& van Knippenberg, A. (2010). Presentation and validation of the Radboud Faces Database. Cognition \& Emotion, 24(8), 1377-1388.

Lee, E., Kang, J. I., Park, I. H., Kim, J. J., \& An, S. K. (2008). Is a neutral face really evaluated as being emotionally neutral? Psychiatry Research, 157(1), 77-85.

Lee, T., Choi, J., \& Cho, Y.S. (2012). Context modulation of facial emotion perception differed by individual difference. PLOS one, 7(3), e32987.

Masuda, T., Ellsworth, P. C., Mesquita, B., Leu, J., Tanida, S., \& Van de Veerdonk, E. (2008). Placing the face in context: cultural differences in the perception of facial emotion. Journal of Personality and Social Psychology, 94(3), 365-381.

Mobbs, D., Weiskopf, N., Lau, H.C., Featherstone, E., Dolan, R., \& Frith, C. (2006). The Kuleshov Effect: the influence of contextual framing on emotional attributions. Social Cognitive and Affective Neuroscience, 1(2), 95-106.

Ngo, N., \& Isaacowitz, D.M. (2015). The cue of context in emotion perception: The role of top-down control, cue type, and perceiver's age. Emotion, 15(3), 292-302.

Pelli, D. G. (1997). The VideoToolbox software for visual psychophysics: transforming numbers into movies. Spatial Vision, 10(4), 437-442. 
Prins, N., \& Kingdom, F. A. A. (2009). Palamedes: MATLAB routines for analysing psychophysical data. http://www.palamedestoolbox.org

Righart, R., \& de Gelder, B. (2008). Recognition of facial expressions is influenced by emotional scene gist. Cognitive, Affective, \& Behavioral Neuroscience, 8(3), 264272.

Sato, W., \& Yoshikawa, S. (2007). Spontaneous facial mimicry in response to dynamic facial expressions. Cognition, 104(1), 1-18.

Schmid-Mast, M., \& Hall, J. A. (2004). Who is the boss and who is not? Accuracy of judging status. Journal of Nonverbal Behavior, 28(3), 145-165.

Sinke, C. B., Sorger, B., Goebel, R., \& de Gelder, B. (2009). Tease or threat? Judging social interactions from bodily expressions. Neuroimage, 49(2), 1717-1727.

Thayer, S., \& Schiff, W. (1974). Observer judgment of social interaction: Eye contact and relationship inferences. Journal of Personality and Social Psychology, 30(1), 110.

Tiedens, L. Z., \& Fragale, A. R. (2003). Power moves: complementarity in dominant and submissive nonverbal behavior. Journal of Personality and Social Psychology, 84(3), 558.

Todorov, A., Said, C. P., Engell, A. D., \& Oosterhof, N. N. (2008). Understanding evaluation of faces on social dimensions. Trends in Cognitive Sciences, 12(12), 455-460.

Webster, M. A., \& MacLeod, D. I. (2011). Visual adaptation and face perception. Philosophical Transactions of the Royal Society B- Biological Sciences, 366(1571), 1702-1725. 


\section{Figure captions}
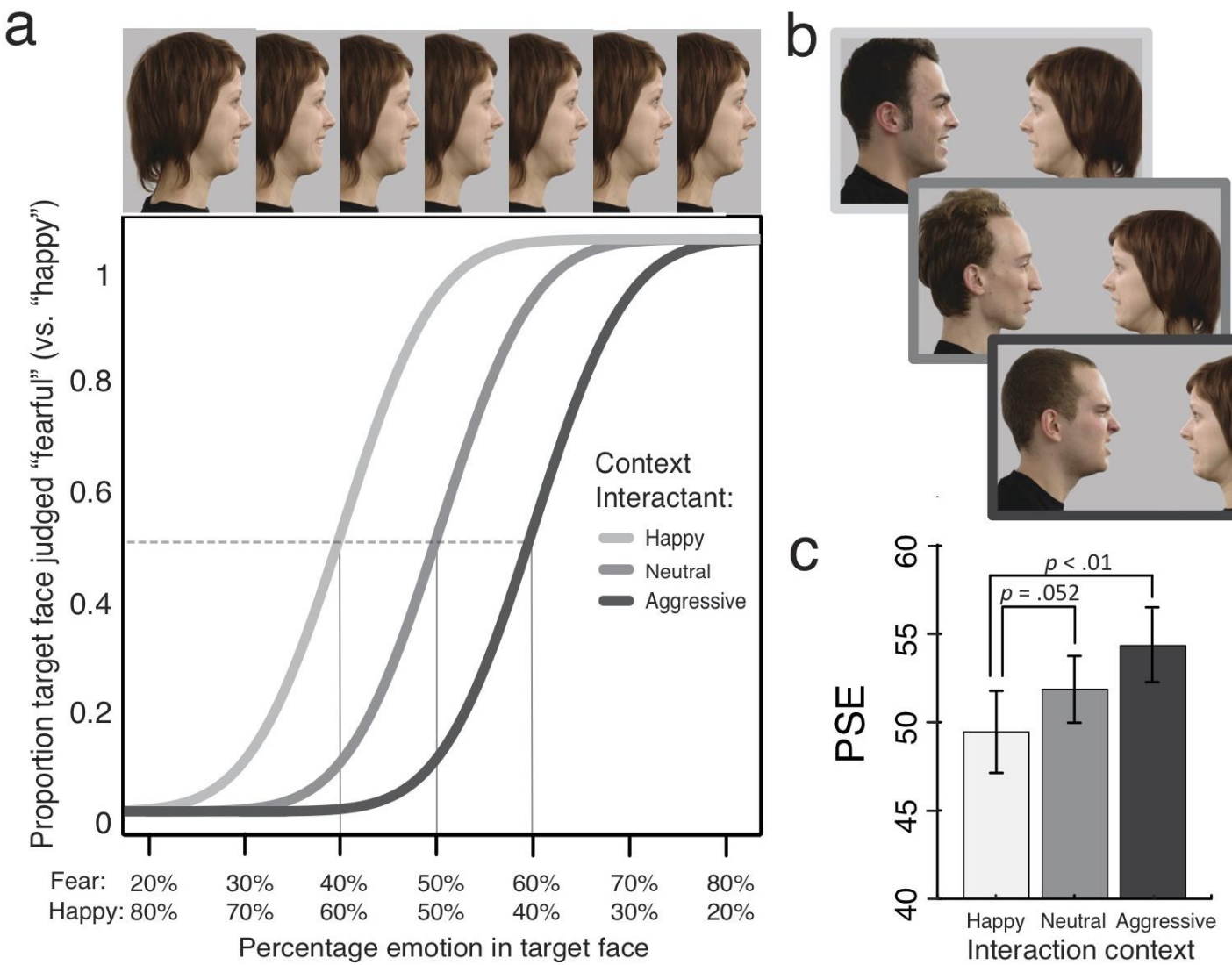

Figure 1. (a) The effect of emotion context was inferred from the difference between the estimated points of subjective equivalence (PSEs) for the three context emotion conditions (psychometric functions pictured are illustrative; dotted line shows the point at which the target is equally likely to be judged fearful or happy). (b) Stimulus configuration in Experiments 1 and 2. Two interactants were presented facing each other, with mutual, direct gaze. (c) Mean PSE for each emotion condition in Experiment 1. Error bars denote \pm 1SEM. 


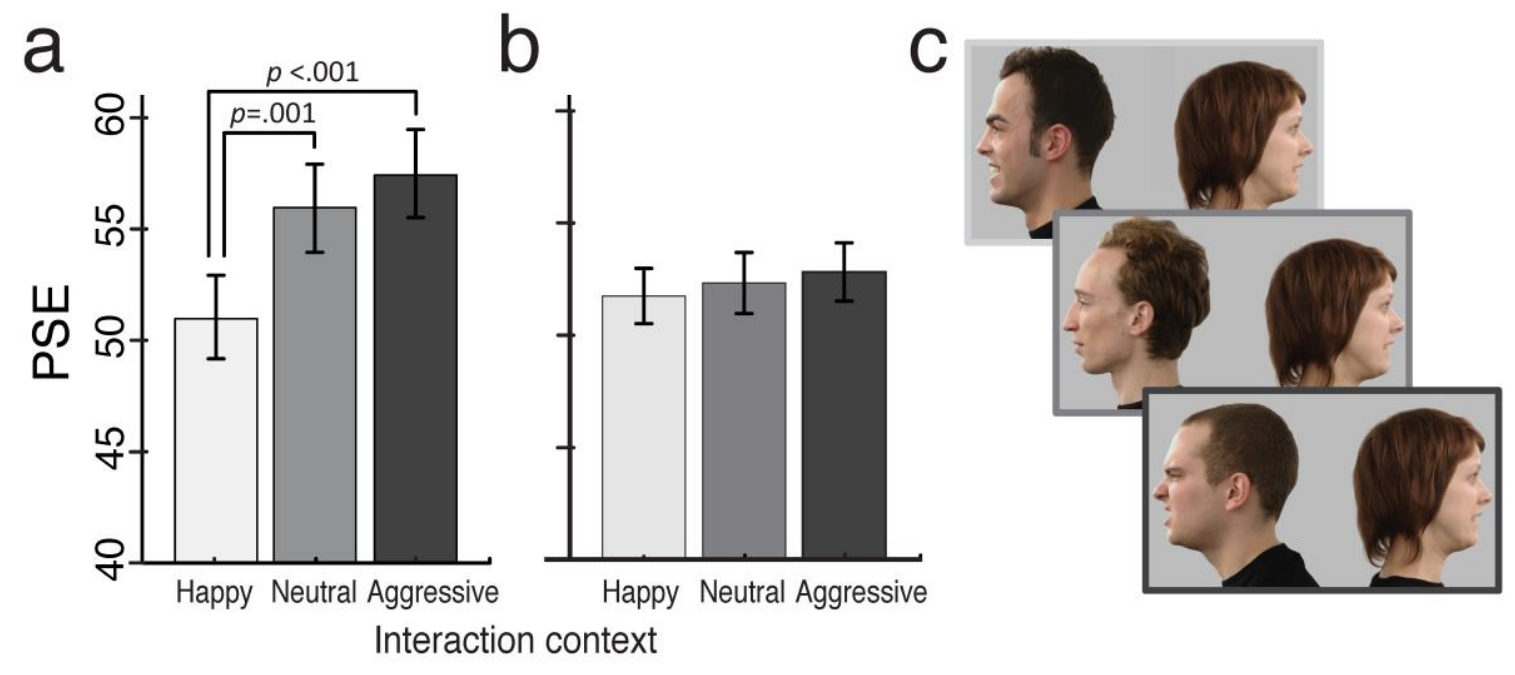

Figure 2. Mean point of subjective equivalence (PSE) for each emotion condition in (a) Experiment 2 face-to-face, and (b) back-to-back conditions. Error bars denote \pm 1 SEM. (c) The back-to-back configuration, where low-level stimulus attributes (such as contrast, spatial frequency) remained the same as the face-to-face condition. 